\title{
Analysis on the Construction Pathway of Information Audit of Accounting Firms in Big Data Era
}

Bei Li

Shandong Women's University, Ji’nan, Shandong, China

\begin{abstract}
At present, with the deepening of the economic and social digital transformation and the use and popularization of big data, accounting firms are once again facing opportunities and challenges for upgrading. How to make full use of modern audit technology and adapt to the background of big data era is an urgent problem to be solved by domestic accounting firms. This paper first analyzes the problems existing in practice, and then puts forward the implementation path of information audit construction in the era of big data, so as to improve the information audit level of Chinese accounting firms and provide some reference for the research of relevant personnel.
\end{abstract}

Keywords: Big data, Information audit, Accounting firm.

\section{Introduction}

In order to promote the digital transformation of the CPA industry, drive the high-quality development of the CPA industry, On April 8,2021, the 7th (communication) meeting of China Association of Certified Public Accountants deliberated and approved the Information Construction Plan of Certified Public Accountants Industry (2021-2025), The development of China's CPA industry has entered a new era, On the one hand, change in audit philosophy, techniques, and methods, accelerate information construction and development, It is the fundamental task of industry construction in the new era; On the other hand, Large-scale application of information technology with big data, artificial intelligence, cloud computing, and blockchain as the core, It also provides more information technology means for the firm. According to statistics, $75.6 \%$ of large accounting firms in China have realized the informatization of internal management and project management in their daily work. Some accounting firms, around the audit business with high frequency and high repetitive nature, have built the sharing center of different functions, improving the practice efficiency. There is a big gap between the information development of small and medium-sized accounting firms and large accounting firms, and there are still some problems in the construction of information audit.

\section{Problems Existing in the Practice of Chinese Accounting Firms}

\subsection{Insufficient Understanding of Information Audit}

Auditors' understanding of information technology and their thinking mode have an important influence on the development of information technology audit. Some auditors do not fully pay attention to the development of information audit environment, and habitually have certain resistance to new things, and have little understanding of big data, cloud computing, cloud audit and other emerging concepts, so as to take a wait-and-see attitude towards the development of information audit work. Due to its lack of understanding of information audit, the original inherent mode is still adopted in the work, which makes it difficult for auditors to adapt to the atmosphere of information audit. The survey found that some accounting firms focus more attention on the growth of business income, auditors pay more attention to the project itself, rely more on audit experience, audit did not adopt a scientific method to understand the project situation and risk in the audit process, and still rely on experience to control risk, which will undoubtedly greatly increase the audit risk.

\subsection{The Lack of Compound Talents}

In the era of big data, auditors must be compound talents. They should not only have firm audit knowledge and skills, but also have computer hardware knowledge, have unique sensitivity to network and system security, and also have a deep understanding of financial accounting and internal control knowledge. At present, especially the lack of IT auditors has become an important factor affecting the development of the firm. The daily transactions in some industries (such as banking) are highly dependent on IT system. Since a large number of transactions of the same nature recur repeatedly, a reasonable sample size is audited, so it must be highly dependent on the reliability of IT system. In auditing, in order to ensure the reliability of the system, first of all, it is necessary to carry out various tests on the core system and related system of the bank. After determining through the relevant tests that the system is reliable, we will only need to use a simple analytical review procedure to complete the audit of major subjects such as interest income and expenditure. However, in the actual audit work, there is often a lack of information auditors who can complete the control and test of the bank IT system, and the auditors can only achieve the audit purpose of confirming the final balance through spot check. Obviously, the correctness of a large number of occurrence through limited sampling samples will not meet the audit objectives, and the audit risk will increase. 


\subsection{Information Infrastructure Construction and Data Security Management should be Further Strengthened}

The primary task of the firm information construction is the information infrastructure construction. The standards and requirements of information infrastructure construction gradually improve with the rapid development and wide application of information technology, the expansion of accounting firms and the increase of auditors. In recent years, although many accounting firms to upgrade the host equipment, storage equipment, network equipment, the existing information network constantly transformation and optimization, but with remote, mobile, instant office, system quality monitoring and risk warning and data analysis of intelligent application goal still have a certain gap. In addition, the emergence of big data technology will also pose a threat to the security of audit data to some extent. Certified public accountants in the audit need to collect a variety of data of the audit unit, which will lead to customers are too worried about the data security problem, they usually do not allow certified public accountants to use audit software directly read data connected with accounting software, which is not conducive to the smooth development of accounting firm auditors.

\subsection{The Audit Software Matching Big Data Needs to be Optimized}

Efficient and convenient audit software is the basic condition for the construction of information audit, but now the audit software used online by accounting firms still needs to be further optimized and upgraded. The rapid development of the Internet has made accounting more and more electronic. In the future audit work, a large number of electronic information and numbers are what auditors will face. Efficient audit software is an important support for auditors to ensure the quality and speed of audit, auditors should master the operation of audit software in a short time, and master how to collect relevant data and information through audit software, and verify and analyze the authenticity of the collected data and information. Although computer information technology has developed rapidly in recent years, the overall level still needs to be improved. In addition, China information audit started relatively late, no relatively mature research and development experience, so fit big data audit software development speed is very slow, a lot of information audit firms online audit software is not completely applicable to audit work, can only data collection and classification, processing, analysis and mining data function need to be improved.

\section{The Construction Path of Information Audit of Accounting Firms}

\subsection{Enhance the Awareness of Information Audit}

Accounting firms to smoothly carry out the construction of informatization audit, first of all require auditors to have a correct understanding of informatization and big data. First, the industry to increase the publicity of big data and information, accounting firms to improve the importance of big data and information audit, guide auditors to change ideas, make it realize the importance of information to audit development, to big data, cloud computing and other new things have a correct, comprehensive understanding, and gradually apply new things to the audit work. Second, the firm should regularly train auditors, organize auditors to actively learn computer knowledge and operation skills, learn how to efficiently use audit software, and ensure the smooth progress of the construction of information audit. In addition, strengthen communication with peer accounting firms, learn from the experience of advanced accounting firms, and improve and process according to the actual practice of the firm. Auditors can use traditional work experience to deepen their understanding and understanding of new things to broaden their working ideas and reduce audit risks.

\subsection{Strengthen the Construction of Compound Talents}

In order to meet the demand of new talents in the era of big data, accounting firms should attach their importance to training and introducing compound talents with the comprehensive ability of financial accounting, information system audit and big data analysis. On the basis of the existing auditors, we will extensively recruit IT technical talents from the society, and a certain number of certified public accountants engaged in securities business and rich professional experience, so as to create a distinctive compound talent team that can become the backbone of accounting firms. Prepare internal technical specification documents such as information audit practice manual, promote information audit experience and skills, regularly training firm practitioners' information knowledge and skills, share experience, exchange learning experience, improve the incentive mechanism, reward employees who progress in information learning, to improve information audit skills, to improve the enthusiasm of information learning, comprehensively improve the information audit level of accounting firm auditors.

\subsection{Strengthen Information Infrastructure Construction and Data Security Management}

Based on the advanced communication technology, we will accelerate the transformation and optimization of the existing information network, enhance the communication capacity of the basic network, enhance the functions of the host equipment, storage equipment and network equipment, and strengthen the planning and construction of the data center and data backup scheme. In the era of big data, in order to efficiently carry out the information audit work and ensure the work efficiency, it is also necessary to attach great importance to the security of the audit data, and focus on the management of the audit data storage platform. In order to ensure the effective development of the work, the existing information audit management system should be continuously improved according to the needs of the audit data storage platform, and used as the criterion for the development of this work. In addition, it is necessary to constantly improve the improvement of big data analysis system, and special data transmission lines are established through logical or physical 
isolation, to manage the data formed in audit information work, so as to fully ensure the security and confidentiality of audit data.

\subsection{Full Application of Information Technology to Build an Audit Platform}

Considering the high development cost of the platform, there may be pressure for small and medium-sized accounting firms, and the industry can lead the construction of the audit platform. On the one hand, it enables small and medium-sized firms to use information audit technology to deal with risks, and on the other hand, to reduce the use cost of small and medium-sized firms. Cloud computing can complete the processing and storage services of big data, and with the development of information technology, I believe that the price of cloud computing services will be lower and lower in the future. Meanwhile, since cloud providers are often giants in the information technology industry, they are far abler to maintain data security than accounting firms. With the help of these cloud computing suppliers, accounting firms, with the unified help and guidance of industry associations, establishing an interconnected cloud audit platform is the key to the comprehensive application of information technology. The development process of big data includes data warehouse, online analysis technology, data mining and data visualization, which finally forms a complete business intelligence industry chain. Four international accounting firms have begun to apply artificial intelligence in the audit, $75.6 \%$ of our large accounting firms in daily work also realized internal management and project management information, some accounting firms around audit high frequency, high repetitive audit business, built the sharing center of different functions, so small and medium-sized accounting firms are also want to grasp the revolutionary breakthrough opportunity of audit technology.

\section{Conclusion}

The development of information audit is related to the development of the audit industry. Under the background of big data with the rapid development of information, the core technology and methods of audit are also changing. The new information audit technology and methods play a very important role in the development of accounting firms. Therefore, if accounting firms want to survive in the fierce competition, they should also conform to the development requirements of The Times, constantly improve the level of information audit, and improve their market competitiveness.

\section{Acknowledgement}

This paper is the research result of the project "Information Auditing Research in the Age of Big Data-Taking $M$ Accounting Firm of Shandong Province as an example" (No. 2017YB02) of the Youth Research Project of Shandong Women's university in 2017.

\section{References}

[1] Industry Information Construction Planning of Certified Public Accountants (2021-2025). [EB/OL]. 2021. https://www.cicpa.org.cn/ztzl1/hyxxhckzl/zcyxs/20210 5/t20210506_61751.html

[2] Su Qi. Practice of Information Construction of Certified Public Accountants takes Zheng hua Certified Public Accountants as an example [J]. Chinese CPA, 2017 (09): 29-32.

[3] Liu Yang. Information Audit Research in the Age of Big Data [J]. Guide to Economic Research, 2019, (01): 98-199.

[4] Chen Li. Six tasks of accelerating the information construction of accounting firms [J]. Chinese CPA, 2019, (11): 34-35

[5] Tang Xuewei, Tong Xiaofeng. Analysis on the Realization Route of Audit Informatization Construction in the Age of Big Data [J]. China Markets, 2021, (17): 195-196. 